PAPER

\title{
Prevalence and intensity of pain after stroke: a population based study focusing on patients' perspectives
}

\author{
A-C Jönsson, I Lindgren, B Hallström, B Norrving, A Lindgren
}

See end of article for authors' affiliations

......................

Correspondence to: Ann-Cathrin Jönsson Department of Neurology, Lund University Hospital, S-221 85 Lund, Sweden; ann-cathrin.jonsson@ skane.se

Received 29 August 2005 In revised form 5 December 2005 Accepted5December 2005

Published Online First 14 December 2005
Objective: To determine prevalence and intensity of pain after stroke, focusing on patients' perspectives. Methods: During a one year period, 416 first-ever stroke patients were included in the population based Lund Stroke Register. After 4 and 16 months (median), 297 patients (98\% of survivors) were followed up. Worst pain intensity during the previous 48 hours was assessed on a visual analogue scale (VAS), range 0 to 100: a score of 0 to 30 was defined as no or mild pain; 40 to 100 as moderate to severe pain. NIH stroke scale (NIHSS) score and $\mathrm{HbAlc}$ were assessed at baseline. At 16 months, screening for depression was done using the geriatric depression scale (GDS-20), and cognition with the mini-mental state examination (MMSE). Predictors of pain were determined by multivariate analyses.

Results: Moderate to severe pain was reported by 96 patients $(32 \%)$ after four months (VAS median $=60$ ). Predictors of pain were younger age $(p=0.01)$, female sex $(p=0.006)$, higher NIHSS score $(p<0.001)$, and raised $\mathrm{HbAlc}(p=0.001)$ at stroke onset. At 16 months, only 62 patients (21\%) had moderate to severe pain, but pain intensity was more severe (median VAS score $=70 ; p<0.016$ ). Higher pain intensity correlated with female sex, worse GDS-20 score, better MMSE score, and raised HbAlc. Pain was persistent in $47 \%$, disturbed sleep in $58 \%$, and required rest for relief in $40 \%$ of patients.

Conclusions: Although prevalence of pain after stroke decreased with time, after 16 months $21 \%$ had moderate to severe pain. Late pain after stroke was on average more severe, and profoundly affected the patients' wellbeing.
$\mathrm{S}$ tudies of pain in stroke survivors have often been concentrated on a clinical diagnostic perspective-for example, central post-stroke pain (CPSP), shoulder pain, or other specific types of pain..$^{1-6}$ Previous studies usually involved stroke patients admitted to stroke units, geriatric clinics, general wards, or rehabilitation units. ${ }^{1-10}$ In these reports, the prevalence of pain after stroke has varied between $19 \%$ and $74 \%$, and pain intensity was not measured. The prevalence of shoulder pain, one of the most common sites of pain after stroke, ranges from $11 \%$ to $40 \%,{ }^{1-4}$ and of CPSP, from $8 \%$ to $35 \% .^{5611}$ Thus the prevalence of pain after stroke has varied considerably in previous studies, presumably because of different inclusion criteria, definitions, and means of follow up. The intensity of pain has not been measured, and little is known about the evolution of pain with time.

The objectives of our study were to determine the prevalence, intensity, and location of pain from the patients' perspectives, as well as the evolution of pain with time and predictive factors in a consecutive, population based group of stroke survivors.

\section{METHODS}

We included 416 consecutive first-ever stroke patients with stroke onset between 1 March 2001 and 28 February 2002 in the Lund Stroke Register (LSR). The LSR covers the population of eight municipalities with 234505 inhabitants (31 December 2001), representing the local catchment area of Lund University Hospital. Stroke was diagnosed according to the WHO definition as rapidly developing signs of focal (or global) disturbance of cerebral function lasting more than 24 hours or leading to death, with no apparent cause other than vascular origin. ${ }^{12}$ This definition includes spontaneous subarachnoid haemorrhage, but excludes subdural and extradural haematomas and transient ischaemic attacks. All patients but one with a final diagnosis of first-ever stroke underwent computed tomography (CT) of the brain. The methods for detecting all first-ever stroke patients during the defined period have been described previously, ${ }^{13}$ and were similar to the procedures used in another Swedish epidemiological report. ${ }^{14}$ Every workday, we screened the daily admission lists at the department of neurology and weekly at the department of neurosurgery, including both hospital inpatients and outpatient clinic patients, with a wide range of admitting diagnoses. The nurse specialist also inquired at other hospital departments every month, and at all nursing homes in the LSR area every three months, as to whether any new cases of stroke had been found. We also sent letters to primary care physicians, asking them to report all stroke cases not referred to hospital. Among the 416 patients, 40 had not been admitted to hospital.

All surviving patients were contacted four months after stroke onset (follow up I) and 16 months after stroke onset (follow up II) (medians) (fig 1), and offered a personal appointment with a nurse specialist (A-CJ) and a physical therapist (IL). These two professionals undertook all follow up assessments. Pain intensity could be assessed on a visual analogue scale (VAS) in 297 patients on both follow up occasions. These 297 patients comprised $98 \%$ of all survivors at follow up II. About $70 \%$ of the patients examined were able to come to the outpatient clinic, and the others were examined in primary care centres $(\approx 10 \%)$, nursing homes $(\approx 10 \%)$, or their own homes $(\approx 10 \%)$.

Abbreviations: $A D L$, activities of daily living; $B I$, Barthel index; CPSP, central post-stroke pain; DVT, deep venous thrombosis; GDS, geriatric depression scale; LSR, Lund Stroke Register; MMSE, mini-mental state examination; NIHSS, National Institutes of Health stroke scale; VAS, visual analogue scale 


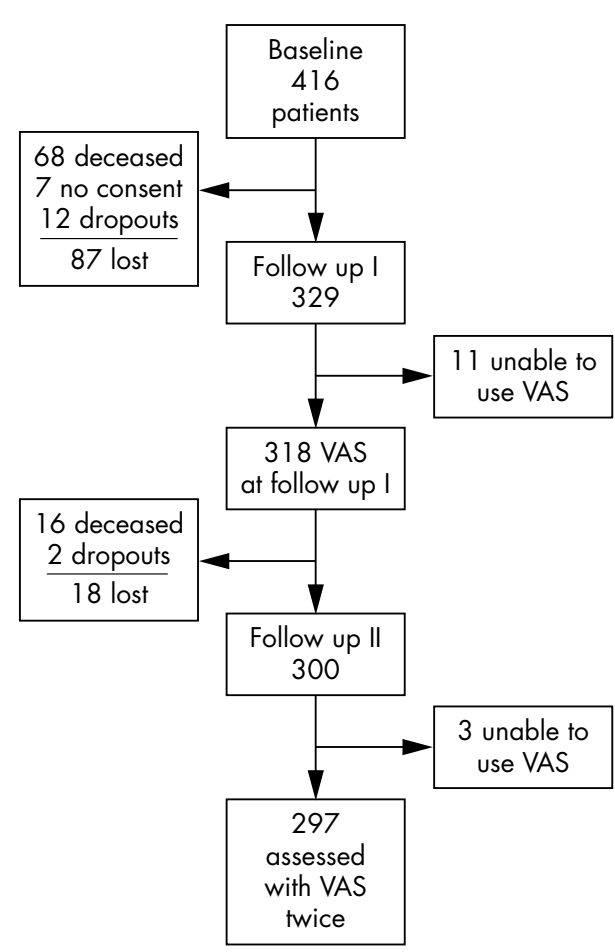

Figure 1 Patient flow diagram. VAS, visual analogue scale.

Informed consent was obtained from each participant or, if the patients were confused or had sensory dysphasia, their spouses or significant others. The study was approved by the ethics committee of the Faculty of Medicine, Lund University.

\section{Baseline assessments}

We registered the following baseline variables: age, sex, main type of stroke, NIH stroke scale (NIHSS) score, ${ }^{15}$ sensory disturbance (item 8 in NIHSS), hypertension (blood pressure after the acute phase $\geqslant 160 / 90 \mathrm{~mm} \mathrm{Hg}$ or pharmacologically treated), cardiac disease (defined as angina pectoris, congestive heart failure, myocardial infarction, atrial fibrillation, previous cardiac surgery), and diabetes mellitus (blood glucose $\geqslant 6.1 \mathrm{mmol} / \mathrm{l}$ or serum glucose $\geqslant 7.0 \mathrm{mmol} / \mathrm{l}$ on repeated measurements, or diagnosed earlier). Impaired glucose metabolism has been associated with joint mobility ${ }^{16}$ and shoulder impairment. ${ }^{17}$ We therefore included glycosylated haemoglobin (HbAlc, upper normal limit 5.3\%) at baseline, to screen for abnormal glucose tolerance. ${ }^{18}$

Functional status before stroke was assessed by interview questions about indoor and outdoor ambulation, dressing, and toileting. ${ }^{19}$ If the patients could manage these activities of daily living (ADL) by themselves they were considered independent. Patients' other physical activities (walking, gardening, swimming, running, and other sports) before stroke were recorded on a scale from 0 (no physical activity) to 4 (almost every day). ${ }^{20}$

The stroke location was defined as subtypes according to the Oxfordshire Community Stroke Project (OCSP) classification system: total anterior circulation syndrome (TACS), large anterior circulation infarct with both cortical and subcortical involvement; partial anterior circulation syndrome (PACS), more restricted and predominantly cortical infarcts; lacunar syndromes (LACS), infarcts confined to the territory of the deep perforating arteries; and posterior circulation syndrome (POCS), infarcts clearly associated with the vertebrobasilar arterial territory. ${ }^{21}$

\section{Follow up assessments}

At both follow up assessments, the patients' functional status was assessed using the Barthel index (BI) ${ }^{22}$ and divided into three grades of dependence: independent (BI score, 95-100), moderate dependence (BI score, 60-90), and major dependence (BI score, 0-55). ${ }^{23}$ We used VAS for measuring the intensity of pain. Patients were asked to indicate their worst self perceived pain during the previous 48 hours on a 0 to $100 \mathrm{~mm}$ VAS, marked at one end "no pain" and at the other end "worst imaginable pain". The VAS scores were registered in $10 \mathrm{~mm}$ intervals. A VAS score of zero was defined as no pain, 10 to 30 as mild pain, and 40 to 100 as moderate to severe pain. ${ }^{24}$ Patients' views on different aspects of pain were explored by a set of questions which included onset time, frequency, treatment, effect on sleep, site, and self perceived cause of pain. The investigators (A-CJ, IL) also assessed whether pain was caused by any of the common complications after stroke, according to previous reports ${ }^{14}$ : CPSP, shoulder pain, pressure sores, or deep venous thrombosis (DVT). If the investigators suspected CPSP, the patient was referred to a neurologist, who diagnosed CPSP according to criteria described in previous studies. ${ }^{511}$ We also recorded the location of the pain. If the patients' cognitive function made the assessment of pain difficult, we also interviewed the spouse, other family members, or contact persons among the nursing home personnel.

At follow up II, we tested cognitive function in 272 of the 297 patients (25 patients could not respond for physical, cognitive, or psychological reasons) using the MMSE, range $0-30,{ }^{25}$ a score of $<24$ indicating cognitive impairment. ${ }^{26}{ }^{27}$

We screened for depression in 288 patients (nine could not respond for physical, cognitive, or psychological reasons) with the Swedish adapted geriatric depression scale, GDS-20 (range $0-20$ ). A score of $\geqslant 6$ indicates possible depression. ${ }^{27-29}$

\section{Statistical analysis}

Using Mann-Whitney test and $\chi^{2}$ tests, we examined if there was an association between the prevalence of moderate to severe pain at both follow up assessments and the specified baseline variables. We also tested with Mann-Whitney test whether there was an association between moderate to severe pain and the Barthel index at each follow up. At follow up II we additionally tested for a possible relation between prevalence of moderate to severe pain and the MMSE and GDS-20 scores. The individual VAS scores of the patients with moderate to severe pain at follow up I and II, respectively, were compared using Wilcoxon signed ranks test. The association of VAS scores at follow up I with the baseline variables, and also with the Barthel index at follow up I, was tested by multivariate stepwise regression analysis. A similar analysis was used to test for an association between VAS scores at follow up II and the baseline variables, the Barthel index at follow up II, the MMSE score, and the GDS-20 score. Probability $(p)$ values of $<0.05$ were considered significant.

\section{RESULTS}

Demographic baseline features of the 297 patients included in the study are shown in table 1 .

The 297 survivors in this study are the persons who were able to assess pain using the VAS scale at both follow up assessments (fig 1). The 119 patients who did not participate in our study were in most cases deceased (84 patients); they were also older (mean age 79.7 years) or had more severe strokes, or both. Before stroke onset, $98 \%$ of the 297 survivors were independent in ADL. They had a comparatively low NIHSS score (mean score $=5$ ) at baseline. Grades of dependency at follow up I and II, respectively, were: 73\%/ 70\% independency; 19\%/19\% moderate dependency; and 8\%/ $11 \%$ major dependency. Women had significantly lower Barthel index scores than men $(p=0.038)$. 
Table 1 Baseline demographics and intensity of pain at follow up I and II

\begin{tabular}{|c|c|c|c|c|c|}
\hline \multirow[b]{2}{*}{ Baseline variable } & \multirow[b]{2}{*}{ All $(n=297)$} & \multicolumn{2}{|l|}{ Follow up I } & \multicolumn{2}{|l|}{ Follow up II } \\
\hline & & $\begin{array}{l}\text { No or mild pain } \\
(n=201)\end{array}$ & $\begin{array}{l}\text { Moderate to severe pain } \\
(\mathrm{n}=96)\end{array}$ & $\begin{array}{l}\text { No or mild pain } \\
(n=235)\end{array}$ & $\begin{array}{l}\text { Moderate to severe } \\
\text { pain }(n=62)\end{array}$ \\
\hline Male & $60 \%$ & $64 \%$ & $52 \%^{*}(p=0.047)$ & $63 \%$ & $52 \%$ \\
\hline Age (years) (mean) & 72.1 & 72.5 & 71.3 & 72.4 & 71.0 \\
\hline Male & 70.5 & 70.7 & 70.0 & 70.6 & 69.9 \\
\hline Female & 74.6 & 75.8 & 72.7 & 75.4 & 72.2 \\
\hline Age range (years) & 17 to 96 & 17 to 96 & 45 to 95 & 17 to 95 & 45 to 96 \\
\hline Hypertensiont & $54 \%$ & $55 \%$ & $52 \%$ & $55 \%$ & $50 \%$ \\
\hline Diabetes mellitus $†$ & $14 \%$ & $12 \%$ & $18 \%$ & $13 \%$ & $18 \%$ \\
\hline Cardiac disease $†$ & $37 \%$ & $36 \%$ & $41 \%$ & $35 \%$ & $45 \%$ \\
\hline \multicolumn{6}{|l|}{ Main type of stroke } \\
\hline $\mathrm{Cl}$ & $89.2 \%$ & $89.1 \%$ & $89.6 \%$ & $89.4 \%$ & $88.7 \%$ \\
\hline $\mathrm{ICH}$ & $6.4 \%$ & $8.0 \%$ & $3.1 \%$ & $6.4 \%$ & $6.5 \%$ \\
\hline SAH & $4.0 \%$ & $3.0 \%$ & $6.3 \%$ & $4.3 \%$ & $3.2 \%$ \\
\hline UND & $0.3 \%$ & - & $1.0 \%$ & - & $1.6 \%$ \\
\hline NIHSS (mean score) & 5.0 & 4.2 & 6.6 & 4.9 & 5.2 \\
\hline Sensory disturbance & $27 \%$ & $22 \%$ & $39 \% *(p=0.003)$ & $26 \%$ & $31 \%$ \\
\hline $\mathrm{HbAlc}>5.3$ per cent & $17 \%$ & $14 \%$ & $24 \% *(p=0.015)$ & $15 \%$ & $27 \%$ \\
\hline
\end{tabular}

*Significant differences between the groups with no to mild and moderate to severe pain.

tDiagnoses in the table are defined in the Methods section.

$\mathrm{Cl}$, cerebral infarction; HbAlc, glycosylated haemoglobin; ICH, intracerebral haemorrhage; NIHSS, National Institutes of Health stroke scale; SAH, subarachnoid haemorrhage; UND, undefined.

At follow up II, $34 \%$ of the patients with no or mild pain and $57 \%$ of the patients with moderate to severe pain scored $\geqslant 6$ on the GDS-20 depression scale $(\mathrm{p}<0.001)$. In the group with no or mild pain, $19 \%$ scored $<24$ (that is, cognitive impairment) on the MMSE scale, but only $9 \%$ scored $<24$ in the group with moderate to severe pain $(p=0.05)$. Pain characteristics reported by the patients are presented in table 2 .

\section{Table 2 Pain characteristics}

\begin{tabular}{|c|c|c|}
\hline $\begin{array}{l}\text { Self reports from patients with } \\
\text { moderate to severe pain }\end{array}$ & $\begin{array}{l}\text { Follow up I } \\
(n=96)\end{array}$ & $\begin{array}{l}\text { Follow up I } \\
(n=62)\end{array}$ \\
\hline \multicolumn{3}{|l|}{ Pain onset } \\
\hline Before stroke & $38 \%$ & $40 \%$ \\
\hline 0-2 weeks after stroke onset & $31 \%$ & $26 \%$ \\
\hline 2 weeks to 2 months after stroke & $14 \%$ & $5 \%$ \\
\hline$>2$ months after stroke & $17 \%$ & $29 \%$ \\
\hline \multicolumn{3}{|l|}{ Pain frequency } \\
\hline Constant & $30 \%$ & $47 \%$ \\
\hline Often & $68 \%$ & $52 \%$ \\
\hline Occasional (<once/week) & $2 \%$ & $1 \%$ \\
\hline Disturbed sleep because of pain & $49 \%$ & $58 \%$ \\
\hline \multicolumn{3}{|l|}{ Self perceived cause of pain } \\
\hline Stroke & $51 \%$ & $36 \%$ \\
\hline Other reasons & $43 \%$ & $56 \%$ \\
\hline Unknown & $6 \%$ & $8 \%$ \\
\hline \multicolumn{3}{|l|}{ Methods which relieved pain } \\
\hline Rest & $50 \%$ & $40 \%$ \\
\hline Movement/changing position & $25 \%$ & $24 \%$ \\
\hline Drug treatment & $42 \%$ & $50 \%$ \\
\hline Transcutaneous nerve stimulation & $0 \%$ & $2 \%$ \\
\hline Physical therapy & $5 \%$ & $5 \%$ \\
\hline Acupuncture & $5 \%$ & $3 \%$ \\
\hline \multicolumn{3}{|c|}{$\begin{array}{l}\text { Methods tried which did not relieve } \\
\text { pain }\end{array}$} \\
\hline Rest & $10 \%$ & $10 \%$ \\
\hline Drug treatment & $15 \%$ & $21 \%$ \\
\hline Transcutaneous nerve stimulation & $3 \%$ & $1 \%$ \\
\hline Physical therapy & $14 \%$ & $11 \%$ \\
\hline Acupuncture & $1 \%$ & $5 \%$ \\
\hline \multicolumn{3}{|l|}{ Location of pain } \\
\hline Upper limbs only & $42 \%$ & $32 \%$ \\
\hline Upper limbs + other sites & $18 \%$ & $13 \%$ \\
\hline Lower limbs only & $14 \%$ & $13 \%$ \\
\hline Lower limbs + other sites & $21 \%$ & $26 \%$ \\
\hline Headache & $7 \%$ & $10 \%$ \\
\hline Various other sites & $13 \%$ & $16 \%$ \\
\hline
\end{tabular}

Prevalence and intensity of pain

At follow up I, 96 patients (32\%; 50 men and 46 women) had moderate to severe pain, 23 reported mild pain, and 178 had no pain (VAS score 0) (fig 2). At follow up II, the proportion of patients with moderate to severe pain had decreased to $21 \%$ (32 men and 30 women), while 12 patients reported mild, and 223 patients no pain. Testing for sex differences within the groups with moderate to severe pain, we found that the mean VAS scores for men/women were 59/66 (NS) at follow up I and $65 / 72(\mathrm{p}=0.044)$ at follow up II.

No less than 51 of the 96 patients with moderate to severe pain at follow up I had no $(n=45)$ or only mild pain $(n=6)$ at follow up II, and the median VAS score for these 96 patients decreased from 60 to $23(\mathrm{p}<0.001)$. Forty five patients had moderate to severe pain at both follow up assessments, whereas 17 of 62 patients with moderate to severe pain at follow up II reported no or mild pain at follow up I. At follow up I, the median VAS score for these 62 patients was 50, and had increased to $70(p<0.001)$ at follow up II. There was a significant difference $(p=0.016)$ when comparing VAS scores of the 96 patients with moderate to severe pain at follow up I (median 60) and the 62 patients at follow up II (median 70).

For patients with moderate to severe pain, evolution with time differed with respect to cause and location of pain (table 2). Among the 96 patients with moderate to severe pain at follow up I, the cause of pain was reported to be stroke by $51 \%$, other reasons by $43 \%$, and of unknown cause by $6 \%$. Among the 62 patients with moderate to severe pain at follow up II, a smaller proportion (36\%) reported the cause of pain to be stroke, $56 \%$ reported other reasons, and $8 \%$ cause unknown. The investigators judged the cause of moderate to severe pain to be stroke related in $57 \%$ of the cases at follow up I and in 37\% at follow up II. Among the 57 patients with pain in the upper limbs at follow up I, 44 (77\%) had shoulder pain. At follow up II, there were only 28 patients with pain in the upper limbs and $19(68 \%)$ of these had shoulder pain. There were only four patients $(\approx 1 \%)$ diagnosed with CPSP. Pressure sores and DVT were not found as a cause of pain in any of the patients.

The 96 patients with moderate to severe pain at follow up I experienced considerable improvement between the two follow up assessments, in both the upper and the lower limbs (table 2). Compared with follow up I, the proportion of 

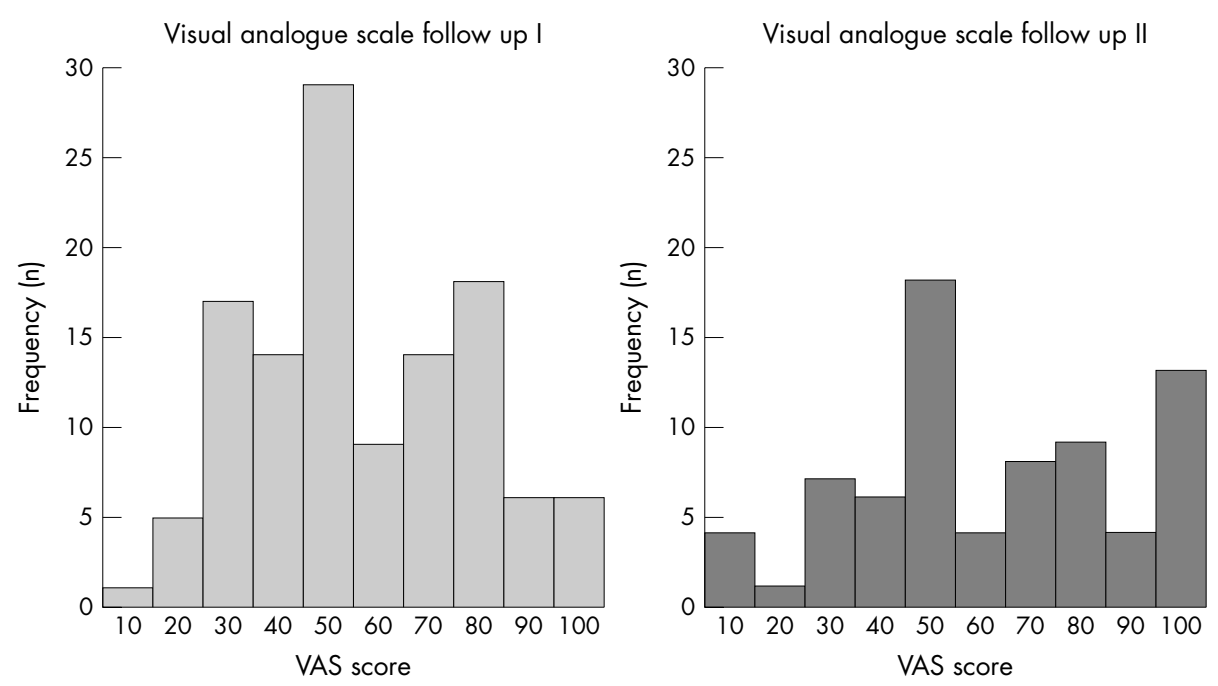

Figure 2 Worst pain during the previous 48 hours reported by the patients at follow up assessments I and II. The same 297 patients were assessed on both occasions; 178 patients at follow up I and 223 at follow up II reported VAS 0 (no pain) and were excluded. The graphs refer to 119 patients at follow up I and 74 at follow up II.

individuals with pain in the upper limbs decreased from $60 \%$ to $45 \%(\mathrm{p}<0.001)$ at follow up II, whereas in the lower limbs there was a small but non-significant increase from $35 \%$ to $39 \%$. Among the 62 patients with moderate to severe pain at follow up II, there were only minor changes since follow up I in the proportion of individuals with pain in the upper limbs (from $50 \%$ to $45 \%, \mathrm{NS}$ ) and in the lower limbs (from $31 \%$ to $39 \%$, NS)

The patients' self reports on pain characteristics are detailed in table 2. Pain was constantly present for 30\%/ $47 \%$ at the two follow up assessments, and often present for $68 \% / 52 \%$. Disturbed sleep because of pain was reported by no less than $49 \% / 58 \%$ of the patients with moderate to severe pain. The proportion requiring temporary rest to obtain pain relief was $50 \% / 40 \%$ and movement/changing position gave pain relief in about a quarter of the patients at both follow up assessments. Half or more of the patients were not relieved from pain by drug treatment and few had tried alternative treatment methods. Physical therapy had been used by only $19 \% / 16 \%$ of the patients. Very few patients had tried acupuncture or transcutaneous nerve stimulation.

Table 3 Multivariate analyses: main findings

\begin{tabular}{lrrrrl}
\hline & \multicolumn{2}{l}{ Follow up I } & & \multicolumn{2}{l}{ Follow up II } \\
\cline { 2 - 3 } \cline { 5 - 6 } & p Value & Coefficient B & & p Value & Coefficient B \\
\hline Sex & 0.006 & 9.8 & & 0.036 & 7.4 \\
HbAlc & 0.001 & 6.5 & & 0.004 & 5.3 \\
Age & 0.010 & -0.4 & & & \\
NIHSS & $<0.001$ & 1.4 & & $<0.001$ & 2.1 \\
GDS-20 & & & & 0.004 & 1.1 \\
MMSE & & & &
\end{tabular}

Variables included in multivariate analyses: Dependent variable: VAS scores at follow up I and II. Baseline variables: sex, age, hypertension, diabetes, cardiac disease, NIHSS score, sensory disturbance, $\mathrm{HbAlc}$, physical activity, main type stroke, OCSP. Barthel index scores at follow up I and II were included, and also MMSE and GDS-20 at follow up II. Only variables with significant values are shown.

GDS, geriatric depression scale; $\mathrm{HbAlc}$, glycosylated haemoglobin; MMSE, mini-mental state examination; NIHSS, National Institutes of Health stroke scale.

\section{Factors related to pain}

The following baseline factors were significantly associated with moderate to severe pain at follow up I in univariate analyses: $\operatorname{sex}(p=0.046)$, sensory disturbance $(p=0.003)$, and HbAlc $(p=0.04)$. Barthel index at follow up I was also related to moderate to severe pain $(p=0.001)$. At follow up II, GDS-20 scores were associated with moderate to severe pain $(\mathrm{p}<0.001)$. In a multivariate stepwise regression analysis, younger age $(p=0.01)$, female sex $(p=0.006)$, higher NIHSS score $(p<0.001)$, and higher HbAlc value $(p=0.001)$ at baseline were significant predictors of more intense pain (higher VAS scores) at follow up I after stroke. At follow up II, a multivariate stepwise regression analysis showed a correlation between higher VAS scores and the following factors: female sex $(p=0.036)$, higher (worse) GDS-20 score $(p=<0.001)$, higher (better) MMSE score $(p=0.004)$, and higher HbAlc baseline values $(p=0.004)$. When doing separate multivariate analyses comparing only possible predictive factors with VAS scores as the dependent variable, we found that besides the mentioned significant baseline variables the clinical stroke subtype LACS $(p=0.044)$ was associated with higher intensity of pain at follow up I, and younger age $(p=0.006)$ correlated with higher VAS scores at follow up II.

\section{DISCUSSION}

This is the first report of prevalence, intensity, and temporary evolution of pain in an unselected group of stroke survivors. The study had a special focus on the patients' perspectives. Our results show that no less than approximately one third of the patients had moderate to severe pain in the first few months after a first-ever stroke, decreasing to $21 \%$ one year later. The latter proportion is close to the $20 \%$ with pain (not specified with regard to intensity and site) after two years in a report of 3203 patients independent on help for primary ADL before stroke. ${ }^{7}$ Because our study included only survivors who could be assessed with VAS scores twice, our group had a rather low mean NIHSS score (5) and a low mean age compared with other studies on selected groups of stroke patients. Only four of our patients were diagnosed with CPSP. This contrasts with a study with 16 cases of CPSP $(8 \%)$ covering a somewhat larger population and with a different study design. ${ }^{5}$ In another study with a considerably 
larger proportion of CPSP (35\%), the patient group was small $(\mathrm{n}=43)$ and selected. ${ }^{6}$

Strengths of our study are the population based design, well characterised patient material, and $>90 \%$ follow up, achieved by examining almost one third of all patients in out of hospital settings. Weaknesses of our study include lack of data on cerebrovascular and other main new events after the index stroke and lack of information on the type and dose of analgesic drug treatment given during the follow up.

One of our main findings was that pain in stroke patients is of a very complex nature. In some cases it was hard to determine whether pain was clearly stroke related or not. Even with pain onset before stroke, the pain intensity could change after the stroke. The pain could be on the same side as the stroke symptoms, or it could be on the opposite side, in both cases possibly related to differences in the patient's balance or motor function, causing stroke induced abnormalities in posture and gait, ${ }^{30}$ or other effects of the stroke. Our study focused on the patient's perspective of pain and how the pain affected the patient's daily life. It is of course also important to determine clinical diagnoses for pain conditions needing special pharmacological treatment-for example, CPSP - in order to offer the patients the required drug, and this was done for the few cases found in our cohort.

One novel finding was that about half the patients with moderate to severe pain early after stroke had no pain at follow up II. However, the group with moderate to severe pain at follow up II had more intense pain than at follow up $\mathrm{I}$, indicating dynamic changes in the occurrence and characteristics of pain after stroke. As in studies of selected groups of stroke patients, ${ }^{1-6}$ we found that one of the most common sites of pain after stroke was the upper limbs, but the prevalence of pain in the upper limbs decreased with time. We intend to further analyse the group with shoulder pain in a separate report.

Another novel finding was that as many as $38-40 \%$ of the patients with moderate to severe pain at the two follow up assessments already had pain before their stroke. Because we had our first contact with the patients as the result of their first-ever stroke, it was not possible to record VAS scores for pain in the past. Consequently we were unable to measure accurately whether stroke aggravated pre-existing pain. No less than $31 \%$ (follow up I) and $26 \%$ (follow up II) of the patients with moderate to severe pain had experienced pain already within two weeks of stroke onset. In a study of chronic musculoskeletal regional pain (regional and widespread) in a general community based Swedish population (20 to 74 years, $\mathrm{n}=2755$ ), the age and sex adjusted prevalence was $34.5 \% .^{31}$ This study group is interesting for comparison because pain in the upper and lower limbs was the most common site of pain in our patient group. The association between higher VAS scores and female sex is similar to the findings in another study reporting that there may be sex differences in the presentation of symptoms in stroke patients. ${ }^{32}$ Women's lower Barthel index score-that is, more impaired functional status-may also contribute to their greater intensity of pain.

The proportion of patients with cognitive decline was significantly larger in the group with no or mild than moderate to severe pain at follow up II. The reason for this is unclear. Cognitively impaired people may be less physically active and therefore avoid movements which provoke pain attacks. It is also possible that some cognitively impaired patients had difficulties in scoring their pain correctly, even if we tried to guide them in how to use the VAS scale.

Previous reports have suggested an association between joint pain, impaired glucose metabolism, and cerebrovascular disease. ${ }^{16}{ }^{17}$ Although diabetes mellitus is well documented as a cause of pain, we did not find any such relation in the present study. However, we found a correlation between pain and raised HbAlc at baseline, which is of interest but needs to be corroborated by further studies.

As presented in table 2, pain had a profound effect on the patients' life situation, because the self perceived frequency of pain was "constant" for 30\%/47\% and "often" for $68 \% / 52 \%$ of the patients with moderate to severe pain at the two follow up assessments. More than half of the patients had difficulties with sleeping because of pain. Lack of sleep may contribute to the post-stroke fatigue which is one of the most common impairments after stroke. ${ }^{33-35}$ Because only $42 \%$ and $50 \%$ of the patients with moderate to severe pain at follow up I and II, respectively, reported relief from pain by drug treatment and one of five patients had tried medication earlier with no effect (table 2), it is possible that pharmacological treatment had not been used sufficiently. Alternative methods reported to relieve pain were movement/changing position $(25 / 24 \%)$, rest $(50 / 40 \%)$, and physical therapy $(5 / 5 \%)$. This concurs with the results of a previous study of pain in a smaller group of stroke patients, showing that other methods besides drug treatment may help to relieve pain. ${ }^{35}$ Our finding of a correlation between functional status, depressed mood, and pain agrees with findings in a previous study of elderly patients. ${ }^{36}$

Our study shows that pain, as reported by patients, is common both early and late after stroke. Although the prevalence of pain after stroke decreased with time, after 16 months, one in five patients had moderate to severe pain. Late pain after stroke was on average more severe, and profoundly affected wellbeing and physical activity. In routine follow up programmes, pain after stroke may be underrecognised and undertreated.

\section{ACKNOWLEDGEMENTS}

This work was supported by grants from King Gustaf V's and Queen Victoria's Foundation, the Swedish Stroke Association, The Pharmacist Hedberg's Foundation, Magn Bergvall's Foundation, the Research Funds of the Department of Neurology, Lund University Hospital, the County Council of Skåne, and Lund University.

\section{Authors' affiliations \\ A-C Jönsson, I Lindgren, B Hallström, B Norrving, A Lindgren, Department of Neurology, Clinical Sciences Lund, Lund University, Sweden \\ Competing interests: none declared}

\section{REFERENCES}

1 Langhorne $\mathbf{P}$, Stott DJ, Robertson L, et al. Medical complications after stroke: a multicenter study. Stroke 2000;31:1223-9.

2 Gamble GE, Barberan E, Laasch HU, et al. Poststroke shoulder pain: a prospective study of the association and risk factors in 152 patients from a consecutive cohort of 205 patients presenting with stroke. Eur J Pain 2002;6:467-74.

3 McLean DE. Medical complications experienced by a cohort of stroke survivors during inpatient, tertiary-level stroke rehabilitation. Arch Phys Med Rehabil 2004;85:466-9.

4 Ratnasabapathy Y, Broad J, Baskett J, et al. Shoulder pain in people with a stroke: a population-based study. Clin Rehabil 2003;17:304-11.

5 Andersen G, Vestergaard K, Ingeman-Nielsen M, et al. Incidence of central post-stroke pain. Pain 1995;61:187-93.

6 Widar M, Samuelsson L, Karlsson-Tivenius S, et al. Long-term pain conditions after a stroke. J Rehabil Med 2002;34:165-70.

7 Glader EL, Stegmayr B, Johansson L, et al. Differences in long-term outcome between patients treated in stroke units and in general wards: a 2-year followup of stroke patients in Sweden. Stroke 2001;32:2124-30.

8 Pullen R, Harlacher R, Pientka L, et al. [The elderly stroke patient observations 18 months after the event]. Z Gerontol Geriatr 1999;32:358-63. 9 Sulch D, Melbourn A, Perez I, et al. Integrated care pathways and quality of life on a stroke rehabilitation unit. Stroke 2002;33:1600-4.

10 Addington-Hall J, Lay M, Altmann D, et al. Symptom control, communication with health professionals, and hospital care of stroke patients in the last year of life as reported by surviving family, friends, and officials. Stroke 1995;26:2242-8.

11 Hansson P. Post-stroke pain case study: clinical characteristics, therapeutic options and long-term follow-up. Eur J Neurol 2004;1 1(suppl 1):22-30. 
12 The World Health Organisation MONICA Project (monitoring trends and determinants in cardiovascular disease): a major international collaboration. WHO MONICA Project Principal Investigators. J Clin Epidemiol 1988:41:105-14.

13 Jönsson AC, Lindgren I, Hallström B, et al. Determinants of quality of life in stroke survivors and their informal caregivers. Stroke 2005;36:803-8.

14 Appelros P, Högerås N, Terent A. Case ascertainment in stroke studies: the risk of selection bias. Acta Neurol Scand 2003;107:145-9.

15 Goldstein LB, Bertels C, Davis JN. Interrater reliability of the NIH stroke scale. Arch Neurol 1989:46:660-2.

16 Arkkila PE, Kantola IM, Viikari JS. Limited joint mobility in non-insulindependent diabetic (NIDDM) patients: correlation to control of diabetes, atherosclerotic vascular disease, and other diabetic complications. J Diabetes Complications 1997;11:208-17.

17 Mäkelä $M$, Heliövaara $M$, Sainio $P$, et al. Shoulder joint impairment among Finns aged 30 years or over: prevalence, risk factors and co-morbidity. Rheumatology (Oxford) 1999;38:656-62.

18 Norhammar A, Tenerz A, Nilsson G, et al. Glucose metabolism in patients with acute myocardial infarction and no previous diagnosis of diabetes mellitus: a prospective study. Lancet 2002;359:2140-4.

19 Glader EL, Stegmayr B, Norrving B, et al. Sex differences in management and outcome after stroke: a Swedish national perspective. Stroke 2003:34:1970-5.

20 Ellekjaer $\mathrm{H}$, Holmen J, Ellekjaer $\mathrm{E}$, et al. Physical activity and stroke mortality in women. Ten-year follow-up of the Nord-Trondelag health survey, 19841986. Stroke 2000;31:14-18.

21 Bamford J, Sandercock P, Dennis M, et al. Classification and natural history of clinically identifiable subtypes of cerebral infarction. Lancet 1991;337:1521-6.

22 Mahoney FI, Barthel DW. Functional Evaluation: the Barthel Index. Md State Med J 1965; 14:61-5.

23 Muir KW, Lees KR, Ford I, et al. Magnesium for acute stroke (Intravenous Magnesium Efficacy in Stroke trial): randomised controlled trial. Lancet 2004;363:439-45.
24 Kelly AM. The minimum clinically significant difference in visual analogue scale pain score does not differ with severity of pain. Emerg Med J 2001;18:205-7.

25 Folstein MF, Folstein SE, McHugh PR. "Mini-mental state". A practical method for grading the cognitive state of patients for the clinician. J Psychiatr Res 1975; 12:189-98.

26 Kase CS, Wolf PA, Kelly-Hayes M, et al. Intellectual decline after stroke: the Framingham Study. Stroke 1998;29:805-12.

27 Kelly-Hayes M, Robertson JT, Broderick JP, et al. The American Heart Association Stroke Outcome Classification. Stroke 1998;29:1274-80.

28 Yesavage JA, Brink TL, Rose TL, et al. Development and validation of a geriatric depression screening scale: a preliminary report. J Psychiatr Res 1982;17:37-49.

29 Gotffries GG, Noltorp S, Norgaard N. Experience with a Swedish version of the Geriatric Depression Scale in primary care centres. Int J Geriatr Psychiatry 1997;12:1029-34.

30 de Haart M, Geurts AC, Huidekoper SC, et al. Recovery of standing balance in postacute stroke patients: a rehabilitation cohort study. Arch Phys Med Rehabil 2004;85:886-95

31 Bergman S, Herrström P, Högström K, et al. Chronic musculoskeletal pain, prevalence rates, and sociodemographic associations in a Swedish population study. J Rheumatol $2001 ; 28: 1369-77$.

32 Labiche LA, Chan W, Saldin KR, et al. Sex and acute stroke presentation. Ann Emerg Med 2002;40:453-60.

33 Glader EL, Stegmayr B, Asplund K. Poststroke fatigue: a 2-year follow-up study of stroke patients in Sweden. Stroke 2002;33:1327-33.

34 Ingles JL, Eskes GA, Phillips SJ. Fatigue after stroke. Arch Phys Med Rehabil 1999;80:173-8.

35 Widar M, Ek AC, Ahlström G. Coping with long-term pain after a stroke. $J$ Pain Symptom Manage 2004;27:215-25.

36 Jakobsson U, Klevsgård R, Westergren $A$, et al. Old people in pain: a comparative study. J Pain Symptom Manage 2003;26:625-36. 